\title{
A construção da representação política do Movimento dos Sem Terra na Bahia: uma experiência no fio da navalha
}

The construction of Landless Movement political representation in Bahia: an experience on a knife edge

Fabya dos Reis Santos - Pós-doutoranda pelo programa CAPES - PNPD junto ao programa de Pós-Graduação da Universidade Federal de Campina Grande. Doutora em Ciências Sociais pela Universidade Federal de Campina Grande (UFCG). E-mail: reisfabya@ yahoo.com.br

\section{Resumo \\ Proponho-me a discutir, neste artigo, algumas dimensões da experiência do Movimento dos Sem Terra/MST na Bahia entre os anos de 1987 e 2011, referente ao processo de construção da participação dos seus membros, nos espaços de representação política institucional (Executivo e Legislativo) e as implicações dessa participação para o processo de "democratização" da política na Bahia e no Brasil. Essa experiência demonstra outros ângulos que contrariam a tese de esvaziamento político dos movimentos sociais em particular do MST, e evidenciam um conjunto de ações atravessadas de conteúdo político e novas dinâmicas para pensarmos a "política" enquanto atividade da práxis humana capaz de transformações sociais.}

\section{Palavras-chave}

Participação política. MST. Representação política. Democratização.

\begin{abstract}
I propose to discuss in this article some aspects of MST experience in Bahia between 1987 and 2011, in the process of building the participation of its members in the areas of institutional political representation (Executive and Legislative) and the implications of such participation to the process of "democratization" policy in Bahia and Brazil. This experience shows other angles that contradict the political emptying thesis of social movements in particular the MST, the disclosure of a set of crossed actions of political content and new dynamics to think "politics" as an activity of human praxis capable of social transformations.
\end{abstract}

\section{Keywords}

Political participation. MST. Political representation. Democratization. 


\section{INTRODUÇÃO}

Proponho discutir neste artigo alguns aspectos da experiência do MST na Bahia entre 1987 e 2011, no processo de construção da participação dos seus membros, nos espaços de representação política e institucional (Executivo e Legislativo) e as implicações dessa participação para o processo de “democratização" da política na Bahia e no Brasil. A discussão está lastreada nas análises conclusivas da tese defendida em 2012 em Ciências Sociais na UFCG.

A experiência do MST na Bahia foi o lócus para a realização da reflexão acerca da participação de lideranças como representantes do MST, no "campo político institucionalizado". Num contextual atual sobre a institucionalização dos movimentos sociais, O MST é paradigmático no caso brasileiro. A experiência que proponho debatermos traz à baila os contornos das dinâmicas implicadas as relações entre dirigentes estaduais e nacionais do MST, quando as lideranças baianas assumem a decisão nas instâncias de direção de participar diretamente do campo institucional, por meio da indicação dos seus membros para disputas eleitorais, e na participação dos arranjos políticos que resultam igualmente na indicação dos seus membros para integrarem cargos na estrutura do estado, assumindo alianças com os governos estadual e federal. Essa experiência torna-se expressiva também para os estudos sociais que apontam a institucionalização do MST, porque traz novos elementos que incrementam nossas reflexões, problematiza, por exemplo, algumas teses, como a de Martins (2000), na afirmação da "negação do político" pelo MST no governo FHC. Essa experiência demonstra outros ângulos que contrariam a tese de esvaziamento político dos movimentos sociais em particular do MST, na evidenciação de um conjunto de ações atravessadas de conteúdo político e novas dinâmicas para pensarmos a "política" enquanto atividade da práxis humana capaz de transformações sociais.

Sublinhei entre os variados aspectos analisados na tese os elementos e as dinâmicas caracterizadores da representação política dos membros do MST-BA, no campo político instituído. Os dilemas, as contradições, as tensões, os conflitos e as ambiguidades decorrentes dessa experiência.. Mencionar rapidamente, para que não gere dúvida, que os elementos teóricos-metodológicos atravessaram e lastrearam as reflexões a que cheguei, e que nesse artigo somente serão debatidas quando necessário para o entendimento das análises apontadas. Os elementos contextuais dessa experiência são os mais enfatizados no artigo e explicitam as particularidades desse tipo de relação estruturada pelos membros do MST na Bahia.

Os fluxos dessas relações foram articulados no âmbito do debate sobre democratização, política e representação política, conceitos estes interpretados como 
processos interdependentes que se encontram inconclusos, perspectivando, portanto, possibilidades para a construção de leituras, interpretações que questionem as assimetrias e as desigualdades no mundo. Apoiei-me ainda numa abordagem processual e figuracional, em diálogo com a obra de Elias, combinada com a reflexão de "campo instituído da política" analisado na obra de Bourdieu (2005); ambas complementadas pelo estudo sobre representação política, democracia e participação política, leitura apreendida heuristicamente, com uma visão heterodoxa dos processos em questão, entendendo a "multidimensionalidade" da participação do MST-BA no processo eleitoral, chamando a atenção que essa relação não acontece apenas nos marcos "institucionais formais" da política brasileira.

Ao se falar sobre as relações entre o MST e o campo político instituído, é recorrente um olhar cauteloso, alertando para os riscos de desmobilização, desradicalização das ações do movimento e do esvaziamento das suas reivindicações frente ao Estado. Ressaltam as ações diretas no âmbito da sociedade civil como mais salutares para a luta social. Sem desconsiderar essas preocupações, problematizo uma visão dicotômica entre Estado e sociedade civil, e a visão que considera as ações no campo político instituído como deslegitimadoras do papel dos movimentos sociais. Nesse sentido, entendo a "multidimensionalidade" da participação do MST-BA no processo eleitoral, salientando que essa relação não acontece apenas nos marcos "institucionais formais" da política brasileira.

\section{A PERCEPÇÃO DOS MEMBROS DO MST SOBRE SEUS DILEMAS NA PARTICIPAÇÃO DO CAMPO POLÍTICO}

Ação "direta" e participação nas eleições, para usar os termos comuns entre os militantes do movimento, em referência à entrada no campo político, também são vistas com muita cautela no MST. Trata-se de um dissenso que ganhou relevo em 1997, quando a Bahia decidiu, nas "instâncias da direção", associar as suas "ações diretas" às estratégias de construção da representação no campo político instituído, conferindo às relações que eram difusamente operadas nesse campo um lugar importante na estratégia de luta do movimento nesse estado. São emblemáticas as relações estabelecidas ao longo da existência do MST, nacionalmente, com diversos segmentos sociais, com vistas a combinar esforços para a construção de uma alternativa de poder à esquerda, e, sem dúvida, o diálogo com o PT se destaca ao se falar numa ação no campo político instituído. 
Desde a fundação do PT e do MST, na década de 1980, essas relações têm sido problematizadas, no início pela demarcação da identidade e autonomia do MST em relação ao partido político, e depois na demarcação dos parâmetros que regulam suas relações, as quais de tempos em tempos são marcadas por momentos de muita tensão, resultando, do lado do MST, por exemplo, na edição em 2008 de uma resolução nacional com orientações à militância para não participar das eleições municipais. Embora esse documento não tenha sido direcionado exclusivamente ao PT, e sim a todas as relações partidárias, ele teve, no alcance prático, uma intensidade maior para as relações com o PT, dadas as aproximações históricas. A resolução da direção nacional, de 14 de março 2008, orienta:

A experiência histórica da classe trabalhadora, em nível internacional e no Brasil, revelou como é nefasta para a organização dos trabalhadores, quando alguma corrente ideológica transforma o movimento de massas em apenas correia de subordinação. Isso gera divisionismos, manipulação e todo tipo de oportunismo. As táticas de luta dos movimentos sociais, para obter conquistas sociais, melhorias de vida e acumularem política e ideologicamente, não podem se submeter apenas a táticas eleitorais, que são próprias da natureza dos partidos. Nosso movimento já experimentou diversas experiências negativas de companheiros/as que se utilizaram do movimento para se eleger, e depois abandonaram os compromissos com a classe trabalhadora. 'Diante desse quadro, tomamos a seguinte deliberação nacional sobre a participação com candidaturas: a) Nosso movimento não deve colocar suas energias, sua militância, sua referência e os poucos recursos econômicos, na disputa eleitoral municipal. b) Nenhum dirigente do movimento, em qualquer nível deve ser candidato. E no caso de algum militante ter vocação eleitoral e quiser disputar as eleições, que é um direito legitimo, deve fazê-lo de forma pessoal e retirar-se da instancia a que pertence. Estarão desautorizados a utilizar os recursos humanos e de infra-estrutura do movimento. E estarão fora das instancias até o final da gestão a que pertence. c) Nenhum companheiro/a assentado ou acampado ou militante poderá ser liberado para cabo eleitoral de candidatos' (MST, 2008).

O texto remete aos dilemas e posições divergentes dos militantes do MST quanto ao apoio ao PT, ou, ainda mais problematizado, se lideranças do movimento deveriam participar diretamente do processo eleitoral, na condição de candidatos(as), ou até mesmo ocuparem cargos políticos. Decorre dessa situação um conjunto de pessoas favoráveis e contrárias, com repercussões diretas para a condução do MST. Tais dilemas têm motivado, em situações pontuais, mas 
consideradas relevantes, o desligamento de militantes $^{1}$, por discordarem de qualquer apoio ou aliança, ainda que seja tática, com o PT; são situações que tensionam as deliberações internas sobre a tática da luta por reforma agrária e por transformação social.

A defesa da neutralidade em relação às eleições brasileiras de 2006 e a deliberação em 2008, que orientava a não participação de lideranças militantes nas eleições são exemplos das tensões vivenciadas. Na Bahia a resolução teve nas suas orientações pouco alcance, uma vez que estava posto pelo conjunto das articulações e relações com o campo político bastante imbricadas e por força da deliberação tomada desde 1997, de modo que as lideranças daquele estado não somente seguiam as relações históricas estabelecidas com o PT, como aprofundaram esse processo com a indicação de algumas das suas lideranças a serem candidatas e a ocuparem cargos na estrutura do estado.

Nacionalmente a resolução foi revogada no início de 2009, numa avaliação da conjuntura política e considerando que na prática, no "tempo da política" (PALMEIRA, 1996) as pessoas de um modo geral tendem a se mobilizar, nesse sentido seria salutar aproveitar essa dinâmica para discutir e qualificar a ação no momento das eleições.

A direção nacional se posicionou quanto à avaliação dos militantes que saíram ${ }^{2}$, reafirmando que o movimento se encontra num processo de avaliação e mobilização em todos os estados, para a construção das linhas e estratégias que

1 Uma carta datada de novembro de 2011, endereçada ao MST, MTD, Consulta Popular e Via Campesina registrou a saída de um conjunto de militantes destas organizações (51 pessoas assinam a carta) por discordarem do projeto estratégico defendido por estas organizações. Segundo elas, estas organizações não atingirão o objetivo da construção do socialismo, julgaram que a tática de se aliarem ao PT, a CUT, está errada. Em um trecho, a carta diz que: "O problema em questão não é que houve uma traição da direção ou um abandono/rebaixamento do projeto político; um erro na escolha das táticas ou dos aliados. A questão fundamental é a contradição entre o objetivo e os caminhos escolhidos para atingir tais objetivos: propúnhamos o Socialismo como objetivo, mas o projeto estratégico que traçamos ou ajudamos a trilhar não nos leva a esse objetivo. Tal estratégia política não é nova na luta de classes: sua origem está na socialdemocracia europeia de há mais de um século, adaptada às condições históricas do Brasil numa versão rebaixada, que foi reproduzida nas últimas décadas pelo PT e CUT e recentemente por MST/Via Campesina, MTD e CP. Atualmente, se apresenta na forma do Projeto Democrático Popular e Projeto Popular para o Brasil”.

2 Carta da direção nacional do MST aos militantes que se desligaram, datada de 24 de novembro de 2011: "Sobre isso, cabe-nos; a) respeitar a decisão que tomaram; b) manter as críticas que nos fazem no âmbito do processo descrito acima; c) desejar que continuem nas lutas da classe trabalhadora, fazendo parte de organizações classistas ou construindo novas formas organizativas capazes de definir e implementar políticas que contribuam para que a classe trabalhadora conquiste uma sociedade sem exploradores e explorados. Os que saíram agora e os que agora voltaram para assinar o documento, certamente nos ajudarão a superar um dos principais desafios da esquerda nos tempos atuais: o de unir a teoria à prática revolucionária. E, estando próximos aos que se esmeram para que haja a hora de dividir, percebam que nenhum processo revolucionário ocorre sem a hora de unir. Que os tempos difíceis de hoje e as práticas políticas de alguns não inviabilizem esse objetivo" (MST, 2011). 
orientarão o movimento no próximo período. Com a revogação da resolução 2008, a direção nacional deliberou um conjunto de orientações para regular a participação no processo eleitoral: a) a avaliação de ter ou não candidaturas seria realizada nos estados, nos espaços deliberativos, nos quais se pesariam os prós e contras, as condições estruturais e conjunturais para colocarem militantes, assentados e lideranças nas disputas políticas; b) havendo candidaturas de militantes que ocupem espaços nas direções do MST, orienta-se que estes se afastem no período eleitoral e durante os mandatos; c) as estruturas para a campanha devem ser fruto da articulação da candidatura, não colocando as estruturas do MST para financiar a campanha. Esses caminhos, permeados de incertezas, ora deliberando resoluções que orientam a não participação nos processos eleitorais, e num período seguinte deliberando em sentido contrário orientado como deve ser essa participação, são nuances exemplificadoras das dificuldades na escolha do caminho a seguir ${ }^{3}$ (MST, 2009).

Esses são dilemas também colocados ao próprio PT, sobretudo a partir da sua chegada à presidência do Brasil. Os arranjos eleitorais, a estratégia de alianças, o programa de governo, a preocupação com a governabilidade e os desafios para transformações sociais historicamente defendidas pelo partido são alguns temas que produzem diferentes tomadas de posição dos seus militantes e lideranças, marcados em certos períodos pela ruptura de um conjunto de militantes com o partido ${ }^{4}$; trata-se de rompimentos e novas construções de tendência ${ }^{5}$, no interior do partido, associados aos momentos de grandes divergências e instabilidade com antigos aliados, como por exemplo, o MST, produzidas pelas incertezas dos rumos do governo. Sem respostas conclusivas, as diferentes posições tomadas por seus militantes, direções e aliados produzem figurações que, para o conjunto dos atores envolvidos bem como para pesquisadores, são de difícil compreensão

3 Outros documentos expressam o posicionamento sobre a participação dos militantes nos processos eleitorais como demonstrado na carta de apoio à candidatura à Dilma Rousseff em 2010. Outro indicativo de escopo maior que faz referência a processos eleitorais é o vídeo de João Pedro Stédile veiculado nas redes sociais pedindo apoio do povo venezuelano à candidatura de Hugo Chaves, em 2012.

4 Heloisa Helena, João Batista-Babá, Fontes e Luciana Genro foram expulsos do PT em 2003, sob a motivação de não obedecerem à orientação do partido em votações importantes, como a da reforma da Previdência, fundaram o Partido Socialismo e Liberdade (PSOL) em 2004; Plínio de Arruda Sampaio saiu do PT em setembro de 2005, ingressou no PSOL; Cesar Benjamin saiu do PT em 2005 por discordar das linhas políticas, filiou-se ao PSOL em 2005, do qual se desfiliou em 2008, e atualmente é editor da Contraponto Editora. Na Bahia, o deputado federal Bassuma foi expulso em 2009, por ser contra ao aborto, por discordar da orientação interna do PT e em divergência com as feministas do partido.

5 O exemplo mais recente foi o rompimento de petistas articulados na tendência Articulação de Esquerda (AE), e a criação de uma nova tendência - Esquerda Popular e Socialista (EPS) com o objetivo de recolocar o socialismo na pauta do PT. Sua fundação aconteceu em 2 a 4 de dezembro de 2011, na Escola Nacional Florestan Fernandes, do MST.

Novos Cadernos NAEA • v. 18 n. $1 \cdot$ p. 89-105 • jan-jun. 2015 
em curto prazo, se suas movimentações e tomadas de posições estariam seguindo para avançarem no projeto de emancipação dos trabalhadores ou se, pelo contrário, estariam aprofundando as situações para mais dominação e opressão dos historicamente "excluídos" e empobrecidos no país.

Esses variados aspectos nos evidenciam como o movimento a partir de um conjunto de debates internos e na interlocução com o contexto social busca dar régua e compasso a sua participação política. Segue o caminho tentando se equilibrar em cenários de grandes incertezas, mas não se pode afirmar, que isso seja negação do político, mas sim um autofazer-se num cenário complexificado com a chegada do aliado histórico político ao governo. Assim, muito menos preocupados em responder as teorias políticas sobre "transformismo" e "cooptação", tentam assegurar suas pautas históricas e um conjunto de demandas para as bases que o integram, bem como, estruturar nas redes internacionais, nacionais e estaduais, acumulação de força para seguir a luta por transformações sociais.

Ainda que possa ter muitas névoas sobre o que será o futuro, por hora me parece que não temos muito claro todas as variáveis para afirmar a tese de cooptação do MST enquanto agente coletivo, por ser ele, assim como muitos no mundo, buscando entender como transitar diante de tantas mudanças sociais. Num esforço para manter o seu vigor, o MST em ano eleitoral, realizou em fevereiro 2014, seu maior congresso nacional com mais de 15 mil delegados que integram suas bases, com 241 delegações internacionais e mais de 500 convidados das suas redes nacionais, colocando-se frontalmente numa mobilização em Brasília para pautar a reforma agrária e justiça social no governo do PT, restando entre outras definições do congresso o fortalecimento da mobilização realizada por um conjunto de organizações populares para realização do plesbicito popular ${ }^{6} \operatorname{com} o$ objetivo de pautar a reforma política no Brasil.

\footnotetext{
O plebiscito popular acontece durante a semana da Pátria, de 1a a 7 de setembro. O de 2014 foi definido na plenária nacional dos movimentos sociais em agosto de 2013, em São Paulo. As organizações envolvidas na mobilização são: Assembleia Popular, Movimento dos Atingidos por Barragens (MAB), Grito dos Excluídos Continental, Movimento Pequenos Produtores (MPA), Consulta Popular, Movimento dos Trabalhadores Rurais Sem Terra (MST), União Nacional dos Estudantes (UNE), Movimento Evangélico Progressista, Via Campesina, Pastoral Operária (PO), Pastoral Carcerária, Central de Movimentos Populares (CMP), Pastoral da Juventude Rural (PJR), Cáritas, Comissão Pastoral da Terra (CPT), sindicatos ligados à CUT, Conlutas, Intersindical, Corrente Sindical Classista (CSC), entre outros. A população em todo o país respondeu a uma única pergunta: "Você é a favor de uma constituinte exclusiva e soberana sobre o sistema político?” Ao final da apuração mais de $95 \%$ dos votantes no plebiscito responderam ser favoráveis a instalação de uma constituinte exclusiva para realizar a reforma política no Brasil.
} 


\section{CONTRIBUIÇÃO DA EXPERIÊNCIA BAIANA AO DEBATE: ELEMENTOS CONTEXTUAIS}

A experiência do MST na Bahia é emblemática nesse processo por ser neste estado o lugar onde de maneira objetiva as lideranças que formam a direção do MST naquele estado levaram a proposta para o debate em suas instâncias e aprovou no encontro estadual em 1997 a estratégia de participação no campo político como forma de construir uma representação no campo político a partir dos "seus". Na busca por compreender esse processo, pude identificar que desde o período de fundação do MST na Bahia as relações com o campo político eram muito próximas. As narrativas das entrevistas oportunizam identificar que as lideranças do MST realizavam concomitantemente ações de organização da luta pela terra e por reforma agrária e para fundação e organização do PT nos municípios baianos. A primeira ocupação foi realizada no Extremo Sul da Bahia, na fazenda 40 45, em 7 de setembro de 1987, uma região marcada por grandes latifúndios, monocultivos de eucalipto e de uma elite familiar que monopolizava os espaços políticos a frente de prefeituras e câmaras de vereadores, bem como operava a mediação com candidatos a deputados estaduais e federais na região. Naquela época a ação do MST naquele estado era duramente combatida pela organização dos latifundiários da região organizados pela UDR.

Ainda no "nascer" do MST na Bahia o lançamento de uma das suas lideranças, a candidata a prefeita de Itamaraju, nas eleições municipais de 1988 é exemplificadora o quão são de longo prazo suas interlocuções na tentativa de adentrar no campo da representação política a partir da indicação dos seus membros, mas sem dúvida na decisão de 1997, essa estratégia ganhou ênfase e produziu uma inflexão nas figurações do MST na Bahia - o lançamento de candidaturas próprias, como forma de construir uma "política de representação" com os militantes do movimento nos espaços do campo político, como câmaras de vereadores, assembleia legislativa, congresso nacional etc, transformaram o que era uma luta difusa, em uma estratégia de construção de representação política, a qual resultou na eleição, em 2006, de um das suas lideranças, Valmir Assunção, deputado estadual mais votado do PT na Bahia; na eleição do próprio Assunção, em 2010, para deputado federal, posicionado entre os quatro primeiros mais votados pelo PT-BA; e na indicação de Vera Lúcia Barbosa, representante da Bahia na direção nacional do MST-BA, ao cargo de Secretaria de Políticas para Mulheres (SPM) na Bahia. Atualmente foi reeleito em 2014, Valmir Assunção a deputado federal e Vera Lúcia foi reconduzida a secretária de estado na pasta de Promoção da Igualdade Racial na Bahia. 
Ao longo desse processo, foram eleitos militantes oriundos do movimento a cargos de vereadores, enquanto outros ocupariam funções de secretários municipais, sendo a ação do MST fundamental para eleger o prefeito de Itamaraju em 1996. Identifica-se um número considerável de militantes e dirigentes que atuam nas direções partidárias, especialmente no PT. As articulações do MSTBA no partido foram fundamentais no Processo de Eleições Diretas (PED), no sentido de eleger o presidente do PT da Bahia, Marcelino Galo ${ }^{7}$, em 2005 , num dos piores momentos da conjuntura do PT; e depois, numa ampla articulação, elegê-lo, em 2010, a deputado estadual. A participação política do MST também conduziu, em 2010, um dos seus dirigentes, Weldes Valeriano Queiroz, à vicepresidência estadual do PT, e em 2014 a secretário dos movimentos populares pelo PT, ações que colocam o MST como um agente ativo nas dinâmicas políticas das quais decorrem as indicações aos cargos no poder executivo, a exemplo das posições de superintendentes, secretários municipais e estaduais, diretores de órgãos federais e estaduais etc. Todavia, mais do que o "êxito" em conseguir ter assento nas câmaras de vereadores, assembleia legislativa e congresso nacional, evidenciam-se as ações dos movimentos sociais'na contribuição para a alteração de posições e agendas na luta política na Bahia, tendo construído uma representação política a partir dos seus membros, como relata Elizabeth Rocha (Representante da Bahia na direção nacional do MST).

À medida que o MST-BA ia se consolidando e ganhando respeito da sociedade, nós achávamos que seria possível lançar alguns dos nossos companheiros as eleições, depois da primeira candidatura com a companheira Rubneuza em 1988, nunca mais tínhamos tentado, então passamos aqueles anos aprendendo, ajudando a organizar o PT, aí fomos construindo a ideia, o entendimento que era importante ter companheiros formados entre nós para nos representar, foi então que lançamos mão no encontro estadual de 1993 no assentamento 4045, da estratégia de ter candidatura própria a deputado estadual. Indicamos o companheiro

\footnotetext{
Marcelino Galo é agrônomo, tem relações muito próximas com o MST desde 1992, atuando como técnico em áreas dos assentamentos; foi, com a ajuda do MST, indicado à Superintendência do INCRA na Bahia, em 2006, e à Secretária da Pesca, em 2009. Sua candidatura à presidência do PT foi objeto de debate nos espaços de deliberação do MST, bem como sua candidatura a deputado estadual.

8 Período de rupturas, relacionadas às denúncias do mensalão, em 2005/2006. Em 14 de setembro de 2005, o mandato de Roberto Jefferson, delator do esquema, foi cassado, suspendendo seus direitos políticos por oito anos. Em 1ำ de dezembro de 2005 foi a vez de José Dirceu ter seu mandato de deputado federal cassado pela Câmara dos Deputados. Os deputados acusados que conseguiram se reeleger nas eleições de 1 o de outubro de 2006, poderão enfrentar mais um processo de perda de mandato.

9 Estiveram na campanha das candidaturas conduzidas pelo MST, em 2010 e 2014, outros movimentos sociais como o Movimento de Luta pela Terra (MLT), Movimentos dos Assentados da Bahia (CETA), Comunidades de Fundo de Pastos, Movimento Atingidos por Barragens (MAB), Movimento do Sem Teto de Salvador (MSTS), entre outros.
} 
Valmir Assunção, mas ele achava que não tinha capital político suficiente. Após outras análises concordamos que talvez não tivéssemos mesmo força pra garantir uma candidatura sozinhos, então, foi aí que entrou Frei Dílson- alguém que era originalmente da Igreja Católica mas que podíamos dizer que também era do MST, considerando sua atuação na época, então fizemos essa aliança. Mas sem duvida ele foi nossa primeira experiência de dizer que tínhamos um candidato próprio. Claro, teve o segmento da igreja que ajudou muito a elegê-lo em 1994, mas na campanha inteira ele era um candidato do MST, aí em 1997 retomamos o debate acumulado sobre as eleições e decidimos no encontro estadual que teria um candidato a deputado estadual foi aí que lançamos o companheiro Valmir Assunção a candidato (Entrevista, maio de 2010).

Identifica-se na narrativa exemplos que sinalizam os primeiros contornos do que viria a ser a estratégia do MST-BA referente à construção da representação política. Ainda segundo os relatos de Elizabeth Rocha sobre as razões de participação política naquele período:

No início do MST aqui não foi fácil, as perseguições foram muitas, éramos vistos por muitos como bandidos, a maioria dos representantes, prefeitos, vereadores, deputados eram ligados aos proprietários de terra, amigos do juiz, do delegado. Tinha uma política muito ruim, sempre humilhavam os trabalhadores, tratavam a prefeitura e o poder político como se fossem suas casas, não, como bem público. Era difícil conseguir junto aos prefeitos da região professores para dar aulas nos assentamentos, construção de escola, melhoria das estradas, creches, ou qualquer coisa. Mas como sabemos o pessoal na época das eleições se envolvem mesmo, aí nos entendíamos que era importante também discutir o poder político com os assentados, como algo importante para avançarmos. Passamos a incorporar na nossa pauta de discussão as eleições, tínhamos muitos cursos para compreender a estrutura do poder político e para também discutir com os assentados. Quais candidatos nesse contexto deveriam apoiar, nosso critério fundamental era defender o MST e a luta por reforma agrária (Entrevista, agosto de 2011).

O trecho acima expõe as primeiras motivações de participação no campo político explicitadas pelas lideranças, isto é, a tentativa de acesso os canais para atendimento das demandas materiais dos assentamentos, como escola, transporte, contratação de professores e busca de apoio à luta pela reforma agrária pelos representantes no espaço institucional, como forma de legitimar o MST em sua bandeira de luta. Conforme explicou Adenilsa Monteiro:

Sobre nossa participação na política tínhamos uma preocupação grande, até porque os assentados eram muitas vezes manipulados no período das eleições por candidatos que no período das eleições até diziam ser a favor da reforma agrária, mas na hora dos despejos violentos, na hora de 
atender as pautas de reivindicação do movimento, não eram solidários, nos viam como coisa menor, sem importância, então tínhamos a necessidade de identificar quem realmente estivesse conosco, quem apoiava nossa luta. Foi necessário de uma maneira pedagógica, debatermos com nosso pessoal, construir uma tática para, se preciso fosse, não deixá-los entrar nos assentamentos. Além do mais, nós buscamos identificar companheiros que nas horas de maior dificuldade estavam conosco, que nos defendesse nos espaços institucionais. As prisões por exemplo, muitas vezes foi necessário o apoio de companheiros deputados como Alcides Modesto do PT para não apanharmos de maneira arbitraria nas cadeias locais, como foi por exemplo no despejo da fazenda Bela Vista em 1988 em Itamaraju (Entrevista, setembro 2010).

Diante do contexto político, o movimento, combinando suas ações diretas de ocupação, de mobilização, buscava uma interlocução com a sociedade. Foram frequentes as articulações com outros segmentos, a fim de construir a imagem do MST na região. Nesse sentido, quando ocorriam as ocupações, as mobilizações e os atos públicos nas ruas dos municípios, o MST buscava a participação de lideranças da igreja (padres, coordenadores das pastorais) dos partidos PT e PCdoB (presidentes do partido, vereadores, deputados estaduais e federais) e com os STR (presidentes, coordenadores), como forma de consolidar apoios a sua luta e principalmente como forma de dar visibilidade aos atos públicos, criando um certo capital político na região - como, por exemplo, o caráter das campanhas de 1988, com Rubneuza Leandro como candidata à prefeita de Itamaraju, que não se elegeu, obteve apenas 525 votos, e a de 1994, com Frei Dílson Santiago a deputado estadual e depois como candidato a prefeito de Itamaraju, em 1996, buscando divulgar o MST enquanto movimento legítimo que atuava na região, e consolidá-lo como agente político no cenário baiano, como relata Elizabeth Rocha:

A eleição de Frei Dílson foi fundamental para consolidar o respeito ao movimento, nós já tínhamos avançado bastante, com muitas ocupações na região, com mobilizações, o povo da região Extremo Sul já sabia identificar bem o movimento, mas claro, ainda com muita desconfiança e um olhar que nós éramos uns vagabundos, ladrões de terra e essas coisas que foi associada no início de construção do movimento. Nessa região que era de muita concentração de terras nas mãos dos latifúndios do eucalipto, a pecuária controlava os espaços de poder político. Ninguém acreditava direito que nós, que o povo sem terra junto, claro, com alguns setores da igreja, apoio do PSB, do PCdoB, conseguiríamos eleger um prefeito na cidade, só que essa eleição (1994) era diferente da de 1988, quando éramos um movimento muito novo, tinha muita repressão das milícias e pouca aceitação da opinião pública mesmo. Por isso, desde lá, colocar a companheira Rubneuza a candidata tinha também esse desejo de apresentar o movimento para sociedade, debater a reforma agrária, acho 
que ajudou de alguma forma, embora tenhamos perdido feio. Internamente tanto os companheiros e companheiras da direção nacional e na Bahia avaliou como importante participar das eleições em 1994 elegendo Frei Dílson a deputado estadual, e depois temos conseguido a prefeitura em Itamaraju em 1996 para ajudar a divulgar as ações do movimento como também conquistar espaços para ajudar a articular a luta por reforma agrária. Mesmo tendo sido apenas três companheiros que se elegerem a vereadores, dois em Itamaraju e um no Prado, porque na hora que o bicho pega nas ocupações serviam pra pelo menos denunciar nas sessões na câmera de vereadores e também para correr atrás de advogados e apoio na sociedade para soltar os companheiros presos (Entrevista, maio de 2010).

Esse processo inaugura uma situação particular: a condução de Frei Dílson Santiago à prefeitura não advinha do "capital familiar" e econômico, representou o investimento de um setor organizado via movimento social, tendo como polo aglutinador o MST, posição que o investiu de uma autoconfiança na disputa eleitoral. Também ajudou na elaboração do discurso sobre a força de mobilização dos sem terras nesse campo. Despontavam, nesse município, os argumentos sobre a importância da representação política a ser realizada pelos membros advindos do próprio movimento. Naquele contexto do movimento na Bahia, não havia grandes polêmicas ou divergências entre membros da direção sobre a participação que estava se dando nas disputas eleitorais. As relações do MSTBA com a direção nacional sobre isso não representaram grandes divergências; a direção nacional analisou, na época, como positiva a conquista da prefeitura de Itamaraju, cidade sede do movimento na Bahia, o que representaria mais um caminho para consolidar o movimento nesse estado. O monumento criado em frente à prefeitura em homenagem ao MST e o modo de o prefeito se referir a Itamaraju, como "a capital da reforma na Bahia", foram exemplos da sintonia sobre o início dessa participação.

Nesse primeiro período, como se pode observar, acontecem as primeiras ações que se misturam às ações diretas do MST, a luta por representação política. É nesse período que identifiquei as dinâmicas que justificam algumas leituras que estou conferindo à representação do MST. Como expressam as análises de Bourdieu (2005), o campo político aparece como forma de ajudar as lideranças do MST na divulgação do próprio movimento como também na luta pela legitimação do movimento junto à sociedade. Nos termos de Bourdieu (2005, p.157):

O mistério do processo de transubstanciação que faz com que o portavoz se torne no grupo que ele exprime só pode ser penetrado por uma análise histórica da gênese e do funcionamento da representação, pela qual o representante faz o grupo que o faz a ele: o porta-voz dotado do pleno 
poder de falar e de agir em nome do grupo e, em primeiro lugar, sobre o grupo pela magia da palavra de ordem, é o substituto do grupo que somente por esta procuração existe; personificação de uma pessoa fictícia, de uma ficção social, ele faz sair do estado de indivíduos separados os que ele pretende representar, permitindo-lhes agir e falar, através dele, como um só homem. Em contrapartida, ele recebe o direito de se assumir pelo grupo, de falar e de agir como se fosse o grupo feito homem.

Busquei, ao longo dessa contextualização, identificar aqueles e aquelas que foram autorizados a falar pelo MST - à medida que constroem o movimento, são também construídas suas identidades coletivas de lideranças, dirigentes do MST. Percebe-se, nesse sentido, como a representação de algumas lideranças é plasmada ao longo do tempo e não no a priori do processo eleitoral. Por isso, identificar as primeiras relações que dão formato ao relacionamento entre o movimento e as lideranças possibilitou verificar como essas lideranças constituíram-se como direção executiva do movimento naquelas circunstâncias históricas e, no decorrer do processo, como algumas dessas lideranças foram autorizadas a atuarem no campo político para representar o MST.

Tal aspecto ilustra que a origem da atuação desses representantes foi e continua sendo plasmada na construção do movimento, por meio das ações diretas, por isso, é correto interpretar a representação no âmbito do movimento como relacionamento e um processo em termos de circularidade, dinâmica que informa como o representante, circular, conecta sua atuação no campo político e no MST. A autorização para representar é construída em termos de circularidade, que é avaliada e reavaliada sob a suspensão se será ou não reautorizada. Identificase, portanto, que ela não é automática e não acontece sem os arranjos avaliativos de prestação de contas nos espaços deliberativos do MST-BA, enfatizando para apreciação da coletividade se de fato e de direito o representante está agindo em conformidade com os interesses, opiniões e expectativas do grupo, ou seja, se está conseguindo manter as conexões e os vínculos com as demandas do movimento e o modo como desempenha suas ações no campo político.

\section{AS DINÂMICAS IDENTIFICADAS NO PROCESSO DE CONSTRUÇÃO DA REPRESENTAÇÃO POLÍTICA}

Há, parece-me, três desafios postos para o MST na Bahia e no Brasil, considerando o fluxo das relações analisadas durante a pesquisa: 1) O desafio em alinhar suas ações no âmbito da sociedade civil enquanto movimento social 
com o Estado, mediar as demandas das famílias que integram o movimento nos seus diferentes pleitos, como por exemplo, as demandas por terra para trabalhar, infraestrutura de moradia, educação, saúde etc. com o Estado caracterizado por suas ausências e dificuldades de atender essas demandas de modo satisfatório e humanitário; 2) o desafio em organizar o conjunto da prática política do movimento como parte da dinâmica da socialização dos seus membros, por meio das marchas, mobilizações públicas, atos políticos e construções de redes com outros atores, traduzindo essas ações em "questão política", em debate que alcance uma materialidade para toda sociedade, como por exemplo, tornar a reforma agrária numa questão relevante para o povo brasileiros; e 3) o desafio em transformar as relações dos movimentos com a política instituída, operada a partir dos partidos e voltada para as disputas eleitorais, como processo de ampliação das esferas de atuação para conformação do seu projeto político que defenda os mais pobres na Bahia e no Brasil.

Nesse sentido, identifico nessa experiência as dinâmicas e os elementos construídos ao longo do processo, visando contribuir para a reflexão, no âmbito das Ciências Sociais, sobre as práticas, os fenômenos e as dinâmicas associadas à construção da representação política do MST. Explicito abaixo de maneira breve alguns fenômenos e dinâmicas, os quais se encontram detalhados no corpo da tese:

a) A partir da ideia do político mediador (KUSCHNIR, 2007), foi possível demonstrar como, nesse processo, o MST plasmou para além da "mediação interna", que consiste no fluxo das relações entre os diversos espaços deliberativos e de direção no interior do movimento, um tipo de ação particular que estrutura a "mediação institucional", dando ênfase aos fluxos entre a atuação no movimento e no campo político, por membros que foram eleitos aos cargos no Executivo e no Legislativo, ligados ao movimento por um projeto político elaborado no MST - projeto que antecede e se prolonga ao período das eleições, atuação dos representantes políticos na construção de "rede de acesso" para atendimento das demandas imediatas dos assentamentos;

b) Aumento do interesse dos assentados, militantes e lideranças em se colocarem para atuar na luta por representação política, gerando uma ampliação do número em alguns municípios de membros que se lançam nas disputas para conseguirem autorização do MST para serem candidatos, principalmente no caso das disputas as vagas para vereadores nas câmaras municipais;

c) a "socialização política dos assentados" decorrente da participação nas atividades do MST, tais como marchas, mobilizações, ocupações etc., como principal lastro do apoio dos assentados aos candidatos oriundos do MST no 
"tempo da política"; combinada também a relações de reciprocidade, valores de gratidão, lealdade;

d) a construção dos arranjos internos no MST, para a combinação das ações diretas e de representação políticas, sobretudo aquelas relacionadas ao "tempo da política".

\section{CONSIDERAÇÕES FINAIS}

As análises dos variados aspectos dessa experiência foram fundamentais para delinear algumas das ações dos movimentos sociais vivenciadas por seus membros que são capazes de construir uma formação sociopolítica junto aos seus pares. Esta formação é voltada para o aprendizado da prática democrática e da ampliação da participação dos espaços públicos (ocupações de terra, prédios, realização de marchas, audiências, ocupações de órgãos, mobilizações, construção de redes nacionais e internacionais, organização de seminários, promoção de cursos formais e informais etc.) e que a construção da sua representação política é uma estratégia que transcende ao fato da indicação de suas lideranças para atuarem nos espaços institucionais da disputa eleitoral, e guarda relação com a produção de uma ação qualificada da "política" e um consequente alargamento das condições para a democratização da política na Bahia e no Brasil.

A entrada de indivíduos com socialização política com compromissos com seus movimentos historicamente estruturados, verificáveis em suas trajetórias de vida, oportuniza uma nova mediação entre representantes e representados, mediação que incluem outras variáveis na construção do debate acerca dos temas comuns relevantes para a esfera pública, superando inclusive as agendas elitistas atuais - até porque não é apenas a capacidade de debater que se apresenta como questão, mas, sobretudo, fazer as disputas para pautar agendas consonantes aos interesses dos cidadãos comuns, e não apenas dos grupos privilegiados historicamente na política. Sensibilidades que oportunizam outras leituras da realidade brasileira e a criação de outras agendas no sentido de superar as tradicionais dicotomias entre os interesses de representantes e representados, construindo assim novos espaços de negociações e contribuições substanciais para alterações de processos tradicionais no "campo político".

Chamo a atenção igualmente ao fato de que, para além do que é e o que deve ser a democracia, haja uma potência que estimule os indivíduos nessa relação; por isso, a importância da minha reflexão para a construção dos portavozes do MST-BA, havendo momentos que nos indicam coexistirem relações 
entre essas dimensões, isto é, ações orientadas para o campo instituído e ações para mudanças das figurações encontradas. Demonstrada também a capacidade de acampados e assentados vivenciarem o tempo das eleições, as eleições vistas não apenas como o momento do consentimento àqueles que tudo farão pela organização, mas como uma confirmação de continuarem construindo outra frente, na qual sabem que precisam continuar atuando via ocupações de terra e reivindicações para inclusive dar força àqueles que autorizarem a mediar espaços sociais para operarem as conquistas do movimento, assim apontando para um novo cenário, no qual eles questionam e alteram as posições de poder na política baiana, introduzem outros valores, quando confirmam, por exemplo, sua capacidade de articulação da candidatura de um dos seus porta-vozes e o tornam o $4^{\circ}$ deputado federal mais votado do PT. Nesse sentido, cito Miguel (2009, p. 175), que diz:

Se não há, aí, nenhuma resposta atual da organização política, existe, ao menos, uma indicação bastante precisa dos valores que devem presidir nossa busca: aprofundamento da justiça, contemplando a diversidade de modos de vida justapostos nas sociedades atuais.

Posicionei a tese junto àqueles referentes que defendem que a contribuição dos movimentos sociais é fundamental para que se tenha efetivamente um alargamento do sentido político e avancemos nos processos democratizantes no país. Na tese não propus a complementaridade como solução simplista, mas como o exercício entre as diferentes frentes de lutas, conexões entre os espaços instituinte e instituído, uma participação via representação advinda dos grupos historicamente excluídos dos espaços instituídos, na problematização das contradições e dos limites no interior do regime democrático representativo, prospectando caminhos para democracia participativa. E, sem dúvida, a maior contribuição desta tese está justamente em nos dirigirmos aos aspectos contextuais, às experiências dos homens e mulheres que se desafiam diante de tantos imperativos para viverem essa experiência que se realiza no "fio da navalha".

\section{REFERÊNCIAS}

BOURDIEU, P. O poder simbólico. Rio de Janeiro: Bertrand Brasil, 2005.

KUSCHNIR, K. Antropologia da política. Rio de Janeiro: Jorge Zahar, 2007.

MARTINS, J. S. A política do Brasil. Lúmpen e místico. São Paulo: Contexto, 2000. 
MIGUEL, L. F. . Democracia, representação e comunidade. In: ARAUJO, C; AMADEO, J. (Org.). Teoria política latino-americana. São Paulo: Hucitec, 2009, v. , p. 159-178.

MST. Documento aprovado em Reunião da direção nacional do MST. São Paulo, Março 2008.

MST. Relatório do debate, 2009. Análise de conjuntura da direção nacional sobre o processo eleitoral. São Paulo. 2009.

MST - Secretaria Nacional do MST. Documentos direcionados aos militantes que sairam dos seus movimentos (Consulta Popular, MTD e Via Campesina). São Paulo, novembro 2011.

PALMEIRA, M. Política no Brasil: visões de antropólogos. In: PALMEIRA, M.; GOLDMAN, M. (Org.). Antropologia, voto e representação política. Rio de Janeiro: Relume Dumará, 1996. p. 181-184 


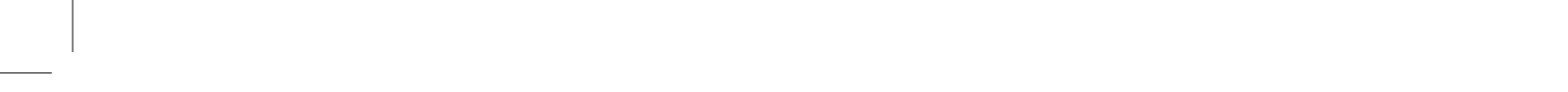

